\title{
Evolution and Equilibrium Strategy of Carbon Emission Behavior of Electric Power Enterprises under Coal Price Fluctuation
}

\author{
Wang Xilian ${ }^{1}$, Jia Xianmin $^{2,3}$, Ciyu Ren ${ }^{1}$ \\ ${ }^{1}$ School of management, Xi'an University of Science and Technology, Xi'an 710054, China \\ ${ }^{2}$ School of management, Xi'an University of Architecture and Technology; Xi'an 710055, China \\ ${ }^{3}$ Business College, Xi'an International University, Xi'an 710077, China
}

\begin{abstract}
Keywords: Evolution, Equilibrium Strategy, Carbon Emission Behavior, Electric Power Enterprises, Coal Price Fluctuation
\end{abstract}

\begin{abstract}
Under the carbon trading mechanism, carbon price is an important market signal, different power companies' environmental costs caused by carbon emissions paice and carbon emissions vary widely, it directly affect the economic profits of power companies. Therefore, this paper studies the evolution and equilibrium strategy of carbon emissions in power enterprises under the fluctuation of coal price.
\end{abstract}

\section{Introduction}

The government's control policy through carbon cap, tight enforcement and carbon reduction policies will affect the scarcity of carbon emissions in the carbon trading market, control the stability of carbon emissions and achieve the goal of government control of carbon emissions. The article argues that carbon price is an important market signal and carbon price fluctuations directly affect the economic behavior of different power companies to promote the rational flow of social funds to optimize the energy structure. Benz and Truck (2006) point out that there are important differences between carbon trading and stock trading. Generally speaking, the value of the stock depends on the expected profit of the company, and the carbon price depends mainly on the total carbon supply and demand in the carbon trading market. Carbon scarcity is susceptible to changes in government climate control policies, progress and diffusion of carbon reduction technologies, fuel efficiency and other factors to induce fluctuations in carbon emissions prices. The government to implement carbon emission control policy severity and set the upper limit of carbon emissions directly affect the carbon emissions of buyers and sellers on the total supply and demand of carbon emissions is expected to change, induced carbon emissions price changes. Thermal power enterprises due to the use of coal, oil, natural gas and other different fossil fuel emissions of carbon emissions vary greatly, to induce power companies to change the cost of electricity generation. Hydropower, wind power, nuclear power and solar power companies because of the use of renewable resources, the release of carbon emissions is much lower than the government set the carbon emissions limit, the transfer of carbon credits can get additional economic benefits. Due to changes in carbon emission prices and changes in carbon emissions to induce changes in power generation costs in different power enterprises, this paper examines the impact of the government's carbon control policies on the economic behavior of different power companies under the carbon trading mechanism.

\section{The Status of Chinese Coal Prices}

Relatively speaking, the overall level of coal prices in China is low and the main performance of the following aspects:

First of all, from the absolute price point of view, the absolute price level of Chinese coal is very low, which is related to Chinese coal price market formation mechanism, after the founding of the Chinese government has been the implementation of low-cost coal products policy, But the implementation of the government to guide the price of coal, coal prices are basically not open, the coal price level has been low. 
Second, from the relative price point of view, Chinese coal prices and international market average coal price difference is still very large, and Chinese coal prices and other energy prices compared to the level of low. According to estimates, in 2002 the world's major energy market coal, coal kerosene, liquefied natural gas and electricity price ratio: 51: 67: 77: 100, while the same period Chinese coal, coal kerosene, liquefied natural gas and electricity price ratio of 7: 49: 37: 100. From Chinese coal procurement costs and the proportion of electricity price point of view, Chinese coal prices are lower, coal prices in the United States is the market price of $50 \%$, while in China only $20 \%$ of electricity prices.

Third, Chinese coal prices and between the ex-factory price is also a big difference. Coal prices are usually from the coal out of ore prices, port prices or intermediate prices and to the composition of the price, and the price of coal mine calculation are based on the price of ore as the standard. As Chinese coal sales in the middle part of the relatively large, and sales of intermediate links cost increases, the final coal mine actually get the price rise income is very small. At present, Chinese electricity prices are almost entirely determined by the market, while the total coal consumption accounted for more than $50 \%$ of the coal price is still the implementation of government guidance, and the coal government guidance price has long been lower than the market price. Even after the government decided to release all the coal prices, the key contract coal price and market coal price gap is still large. At present, the real sense of mutual consultation to determine the mechanism of coal prices has not yet formed. The price difference between coal and coal is still large. At the end of September 2008, the average price of large state-owned enterprises was $720 \mathrm{RMB} /$ ton, which was $220 \mathrm{RMB} /$ ton lower than the average selling price of commodity coal at $940 \mathrm{RMB} / \mathrm{ton}$.

\section{The Definition of the Power Industry}

The National Electricity Regulatory Commission (SERC) divides the power system into four aspects: power generation, transmission, power supply and electricity. The first three belong to the power industry. National Bureau of Statistics in turn the power industry in power and heat production and supply under the category, is divided into two parts of power production and power supply. Among them, the so-called power generation part of the SERC and the National Bureau of the corresponding power production, the SERC transmission and power supply in two parts and the National Bureau of the corresponding power supply. More specifically, the power industry is to convert all types of primary energy through a corresponding variety of power generation equipment into electrical energy and deliver power to the end user to provide end users with different voltage levels and different reliability requirements as well as other basic ancillary services for power industry.

\section{The Impact of Carbon Emissions Control on Economic Behavior of Power Companies}

In order to simplify the model analysis variables, it is assumed that the electricity market and carbon emissions trading market are fully competitive market, the market development is more mature, the participants do not exist arbitrage behavior and no transaction costs. Power companies are divided into two categories: one is coal, oil, natural gas and other fossil fuel power generation of high-carbon power plant; the other is based on hydropower, wind power, nuclear power and other renewable resources power generation low-carbon power plant.

The lower the carbon limit, the higher the amount of carbon emissions purchased from the carbon emissions market in the short term, and the more environmental costs to meet the carbon emission reduction targets. The higher the carbon price, the greater the cost of carbon emissions, the greater the average cost of power plants. Power plants to improve fuel efficiency and reduce the marginal cost of carbon reduction, that is, the smaller the conversion price, power companies will actively use carbon reduction technology to reduce the actual carbon emissions. When coal prices rise, the electricity companies will choose low carbon emissions of oil or natural gas as an alternative fuel, on the contrary natural gas prices, electricity companies will choose high carbon emissions of coal or oil as 
an alternative fuel to reduce the total carbon emissions to reduce the cost of buying carbon emissions. Long-term high-carbon power plant focus and funds engaged in carbon emission reduction technology research and development, to expand the popularization and application of carbon emission reduction technology, efforts to reduce the actual carbon emissions, to fulfill the government set carbon emission reduction targets.

\section{The Government's Implementation of Carbon Emissions Control Strategy}

In this paper, the analysis of economic behavior of fossil fuels and renewable energy enterprises shows that under the carbon trading mechanism, the government can implement the following strategies and use the market mechanism to stimulate different types of electric power enterprises to make the correct economic decision-making and adjustment Their own economic behavior, to achieve the goal of carbon emission reduction and promote sustainable economic development.

Build a mature carbon trading market. According to the early stages of the development of the EU carbon trading market, there are arbitrage behaviors in the carbon trading market, and the volatility of carbon trading prices is very high. Carbon emissions trading mechanism, the carbon emissions trading price is a strong price signal, encourage different enterprises to adjust economic behavior decision-making to adapt to the government carbon emission control policy. If the carbon trading market is immature and the carbon trading price signal fluctuates violently, the electricity production and economic behavior of the enterprises are also greatly affected. The government cannot use the market mechanism to solve the total carbon emission control. Carbon trading market is not perfect, carbon emissions transaction costs are higher, the efficiency of carbon emission reduction. There are many loopholes in the laws, regulations and carbon emission measurement standards and methods related to carbon trading. Non-compliance enterprises are not subject to severe economic penalties that the government should have, so that enterprises can generate speculative behavior and moral hazard. Business decision makers will produce adverse selection, which is not conducive to the implementation of long-term government carbon control.

The price stability of carbon emissions. Carbon emissions prices are an important market signal, the main body of the transaction through the level of carbon emissions automatically adjust the economic behavior of enterprises. Higher carbon trading price signal, high-carbon power companies to increase the carbon cost of additional energy and funds for carbon reduction technology innovation and popularization applications, efforts to reduce the total amount of carbon emissions; low-carbon power companies due to the transfer of carbon emissions get more compensation income, encourage enterprises to continue to expand production capacity, increase power production. Carbon price signals to promote social funds from high-carbon power plants to low-carbon power plants to stimulate the power companies to actively carry out low-carbon technology research and development, optimization of energy structure, control the total amount of carbon emissions.

The government's control policy of implementing carbon emissions. The scarcity of government control of carbon emissions directly affects the stability of the price of carbon emissions, but also directly affects the economic benefits of the transfer of carbon emissions from electric power enterprises engaged in renewable resources. The government can control the scarcity of carbon emissions by implementing a series of drivers such as the stability of the carbon emission control policy, the upper limit or baseline of carbon emission allocations, the distribution or regional distribution of carbon emission controls to influence the economic behavior decisions of different power companies.

The extent to which carbon suppliers and carbon emissions in carbon trading markets depend on the level of total carbon emissions set by the government. If the total amount of carbon emissions set by the government is high, the total carbon demand in the carbon trading market is declining, and the number of carbon demand is reduced. If the total carbon supply in the carbon market is constant, resulting in carbon trading prices, the number of carbon emissions transactions is also reduced. The government set the carbon emissions limit to be stable reducing the participants on the carbon supply and demand is expected to change to ensure the stability of carbon emissions prices. 
In December 2009 Copenhagen's "post-Kyoto Protocol" final signing there are still many unknowns, governments to implement carbon emission control policies there is a lot of instability, a direct result of the total supply and demand of carbon emissions instability. If the government's environmental legislation and regulatory policies for carbon emissions change, the implementation of legislation and policies by government implementers is not so severe that some non-compliance firms have drilled legal loopholes and are not subject to economic penalties; or governments to default of the punishment is too light cannot achieve the deterrent effect, then the government to control the implementation of the total amount of carbon emissions policy effect on the big discount. The government to establish effective monitoring, monitoring, verification and confirmation of real-time information network, once found that default enterprises must implement severe economic sanctions, increase corporate default costs and credit risk costs, to avoid some enterprises to drill government policy policies loopholes.

The government's policy of implementing carbon emissions directly increases the economic costs of high-carbon enterprises and affects the competitive advantage of these firms. For the enterprises involved in the carbon reduction of substantive actions, the government according to the proportion of carbon emission reduction to give some financial compensation; enterprises to carbon emission reduction technology research and development and application of innovation, the government to give some financial support or financial subsidies. The government can use economic means such as carbon emissions to seal the auction or impose a carbon tax, the auction or the carbon tax to obtain the financial income for carbon reduction technology research and development of financial subsidies or the implementation of compulsory emission reduction enterprises to give economic compensation.

\section{Conclusion}

Carbon price is an important market signal in the carbon market transaction. The price of carbon emissions directly affects the economic behavior decision of different power enterprises in the electricity market. Under the carbon trading mechanism, the government implemented a carbon emission control policy to promote social funds from high-carbon power enterprises to a reasonable flow of renewable energy enterprises to optimize the energy structure and control the total amount of carbon emissions.

\section{Acknowledgment}

The National Natural Science Foundation of China(Grant No. 71303184); The Humanities and Social Science Research of The Ministry of Education Youth Project of China (Grant No. 12YJC790075); The Humanities and Social Science Project of Shaanxi Bureau of Education(Grant No.13JK0221); Social Prosperity Project of Xi'an University of Science and Technology(Grant No. 2012SY02).

\section{References}

[1] B. N. Ma, An econometric analysis of Chinese energy demand, J. Statistical Study. 44 (2010) 146-147.

[2] H.X.Zeng, The impact of energy prices on energy intensity, J. Trade Finance. 18(2005) 55-57.

[3] J.H.Xue, Establishing government procurement system initial ideas, J. Coastal Economy, 32(2012) 189-190.

[4] Y.J.Qi, Government procurement system: international experience and reference, J, China Reform, 4(2007) 38-40.

[5] Y.M.Tian, An empirical study on the relationship between technological progress and energy intensity, J. Resource Science, 9(2013) 142-150. 